\title{
Bestimmung von Glibenclamid mit Radioimmunoassay und Hochdruckflüssigkeitschromatographie im Serum von Diabetikern
}

\author{
G. Lindner, L. Herbertz, H. Reinaver
}

Biochemische Abteilung des Diabetes-Forschungsinstitutes an der Universität Düsseldorf

\section{Zusammenfassung:}

Die durchgeführten Untersuchungen ergeben, daß die hochdruckflüssigkeitschromatographische Methode einfacher, schneller und weniger störanfällig als der Radioimmunoassay ist. Nachverdünnungen sind bei diesem Verfahren nicht erforderlich. Die Empfindlichkeit der Methode reicht zyr Bestimmung der Glibenclamidkonzentration im Serum von Altersdiabetikern aus. Der Vorteil liegt neben der Einfachheit der Probenvorbereitung in der gleichzeitigen Bestimmungsmöglichkeit von Glibenclamid neben Tolbutamid und Glibornurid.

Schlüsse/wörter:

Therapiekontrolle - Diabetes - Sulfonylharnstoffe - Bestimmungsmethoden

\section{Summary:}

Blood levels of sulfonylureas have been determined by radioimmunoassay and high performance liquid chromatography. HPLC has some advantages over radioimmunoassay: The serum can be used without dilution, the sensitivity of HPLC is high enough and gives a good accuracy in the therapeutic range of sulfonylureas, and the preparation of samples is simpler in our hands. Simultaneous determination of glibenclamide, tolbutamide and glibornuride can be performed with HPLC.

Key words:

Therapy control - Diabetes - Sulfonylureas - HPLC and RIA.

\section{Einleitung}

Die Serumkonzentrationsbestimmung von Sulfonylharnstoffen erleichtert die Stoffwechselführung von Altersdiabetikern und ist in bestimmten Fällen notwendig. Eine eindeutige Indikation zur Erfassung des Serumspiegels von Sulfonylharnstoffen ist gegeben bei Verdacht auf eine Unter- oder Überdosierung, bei gestörter Elimination infolge einer Leber- und/oder Niereninsuffizienz, aber auch bei Resorptionsstörungen. Die zu erwartenden Serumkonzentrationen liegen bei Glibenclamid im ng-Bereich, also um den Faktor 1000 niedriger als bei Tolbutamid.

Der analytische Nachweis von Glibenclamid erfordert eine ausreichende Empfindlichkeit der Methoden, denn die therapeutischen Konzentrationen liegen bei 700$1200 \mathrm{ng}$ Glibenclamid/ml Serum $(1-4)$.

Erst mit Hilfe des Radioimmunoassays war es möglich, die Glibenclamidkonzentrationen im Patientense- rum quantitativ zu bestimmen (4). In der vorliegenden Arbeit wird der Radioimmunoassay mit einer neuen hochdruckflüssigkeitschromatographischen Methode verglichen.

\section{Methode}

Zur Durchführung des Radioimmunoassays nach Hrstka und Schmidt (4) wird Serum mit tritiummarkiertem Antigen ${ }^{*}$ ) und einem spezifischen Antikörper ${ }^{*}$ ) bei $0^{\circ} \mathrm{C}$ inkubiert. Danach wird innerhalb von 2 Minuten der Antigen-Antikörper-Komplex an Amberlite CG 400 gebunden. Nach dem Zentrifugieren wird der Überstand mit Instagel versetzt, und die freie Aktivität im Scintillationzähler gemessen. Die Auswertung erfolgt über eine Eichkurve. Im unverdünnten Serum sind mit dieser Methode 5-40 ng Gilbenclamid/ml Serum meßbar (Abb. 1).

Zur Bestimmung von Glibenclamid im Serum mit Hilfe der Hochdruckflüssigkeitschromatographie 
Abb. 1:

\section{Aufarbeitungsschema bei der Bestimmung} von Glibenclamid mit Radioimmunoassay.

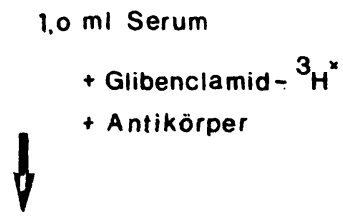

4

$+1,0 \mathrm{ml}$ Amberlite CG 400

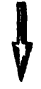

2 min. Rotationsschüttler

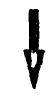

$10 \mathrm{~min}$. bei $3000 \mathrm{Upm}$ zentrifugieren

4

$-1,0 \mathrm{ml}$ Überstand $+3,0 \mathrm{ml}$ Instagel

B-Counter
Abb. 2:

Aufarbeitungsschema bei der Bestimmung von Glibenclamid mit Hochdruckflüssigkeitschromatographie.

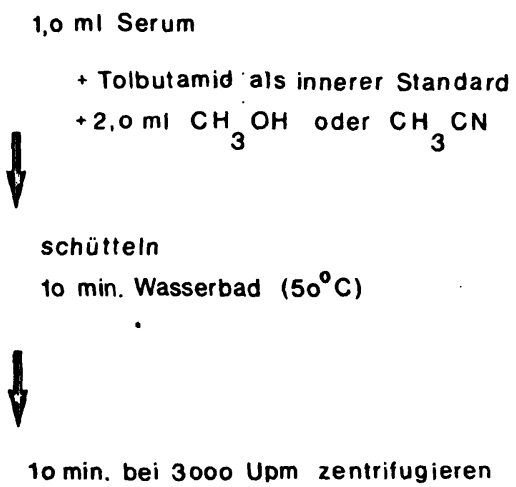

6 Gesamtüberstand

im Rotationsverdampfer trocknen

4

Wiederaufnahme in $1.0 \mathrm{ml} \mathrm{HPLC-Eluens}$

1

HPLC wird Serum, nach Zugabe des inneren Standards (Tolbutamid), mit Acetonitril versetzt. Nach 5 Minuten Schütteln verbleibt die Probe 10 Minuten im Wasserbad bei $50^{\circ} \mathrm{C}$. Der Ansatz wird dann 10 Minuten bei 3000 Upm zentrifugiert und der Gesamtüberstand im Rotationsverdampfer getrocknet. Der Rückstand wird in Eluens aufgenommen und anschließend zur Trennung auf die Säule gegeben. Die hier beschriebene Arbeitsweise ist eine Standardmethode. Je nach vorhandener Serummenge kann der Ansatz auch entsprechend geringeres Volumen haben (Abb. 2).

\section{Apparative Ausstattung}

Zur hochdruckflüssigkeitschromatographischen Trennung wurde das Gerät Typ S111 von Siemens einge- setzt. Die Extinktion wird bei einer Wellenlänge von $230 \mathrm{~nm}$ mit dem Spektralphotometer PM 2 DLC von Zeiss gemessen und mit einem Kompensationsschreiber registriert.

Die mobile Phase besteht aus Acetonitril und 0,05\%iger Phosphorsäure im Verhältnis 45:55. Auch ein Methanol-Wasser-Gemisch führt zu geeigneten Auftrennungen. Die Dosierung erfolgt per Schleife. Zur Trennung benutzen wir eine $250 \mathrm{~mm} \times 3 \mathrm{~mm} \mathrm{Li}$-Chrosorp RP 18 Säule mit einem mittleren Teilchendurchmesser von $5 \mu \mathrm{m}$.

Die quantitative Auswertung erfolgt mit Hilfe einer Eichkurve, die mit verschiedenen Reinsubstanzkonzentrationen erstellt wird. 
Abb. 3:

HPLC-Auftrennung von Reinsubstanzen und Patientenserum. Tolbutamid wird als interner Standard mitgeführt.

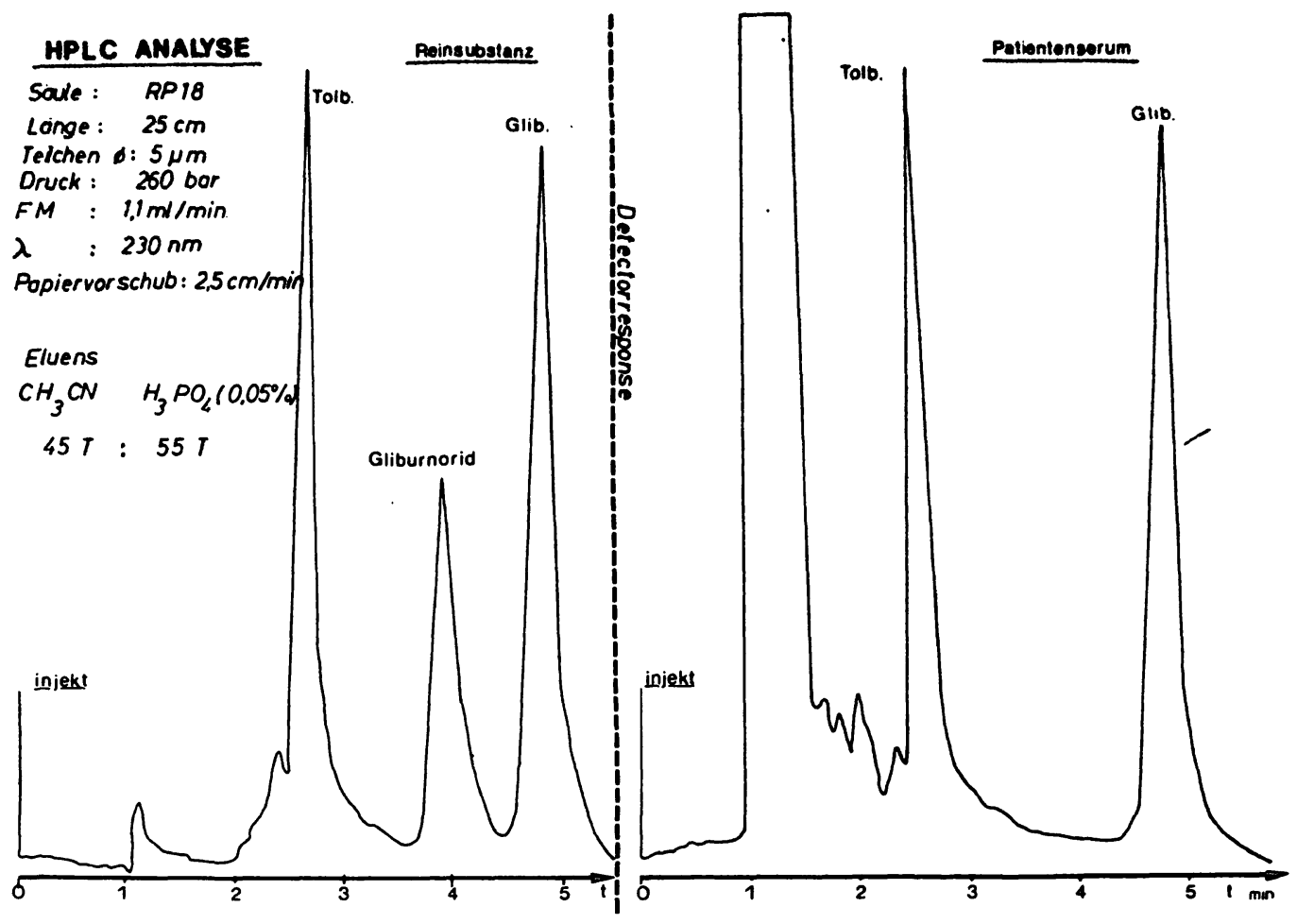

\section{Ergebnisse und Diskussion}

Tolbutamid $^{\circledR}$, Glibenclamid ${ }^{\circledR}$ und Glibornurid ${ }^{\circledR}$ können in einem Lauf problemlos getrennt werden (Abb.3). Alle drei Pharmaka haben unterschiedliche Retentionszeiten und ermöglichen dadurch eine gleichzeitige und quantitative Bestimmung. Auch im Patientenserum wird Glibenclamid unter den angegebenen Bedingungen von allen störenden Begleitsubstanzen getrennt (Abb.3). Sowohl die Arbeitsbedingungen der Hochdruckflüssigkeitschromatographie als auch die Retentionszeiten der Pharmaka sind der Grafik zu entnehmen (Abb. 3). Eine Variation der Retentionszeiten ist durch Änderung des Verhältnisses von Acetonitril zu Phosphorsäure erreichbar.

Bei der Präzisionsbestimmung von 10 Läufen ergibt sich ein Variationskoeffizient von 4\%. Die Richtigkeitskontrolle nach Substanzeinwaage ergibt eine Wiederfindung von durchschnittlich $94 \%(n=10)$. Bei der hochdruckflüssigkeitschromatographischen Methode ist das Detektorsignal in dem von uns überprüften Bereich von 50-1200 $\mathrm{ng}$ Glibenclamid/ml Serum linear. Damit ist der gesamte therapeutische Bereich von 200-1200 ng Glibenclamid/ml Serum abgedeckt. Beim Radioimmunoassay besteht hingegen Linearität nur im Bereich von 5-40 $\mathrm{ng}$ Glibenclamid/ml Serum (4). Somit muß die Bestimmung der Glibenclamidkonzentration mit dieser Methode im verdünnten Serum erfolgen (Abb:4). Ein weiterer Vorteil der Hochdruckflüssigkeitschromatographie besteht darin, daß mit dem beschriebenen Verfahren neben Glibenclamid auch seine Metabolite erfaßt werden können. Die Metabolitbestimmung ist besonders bei Patienten mit einer Eliminationsstörung von Bedeutung. Der geringe Aufwand der Probenvorbereitung für die Hochdruckflüssigkeitschromatographie ermöglicht eine schnelle Überprüfung der Glibenclamidkonzentration und ist auch iny der klinischen Routine einfach durchführbar. Die Aufarbeitung der Probe beansprucht außerdem weniger Zeit als die anderen, in der Literatur beschriebenen Verfahren $(5,6)$. 
Abb. 4:

Eichkurven und Meßbereich bei der Hochdruckflüssigkeitschromatographie und beim Radioimmunoassay.

HPLC

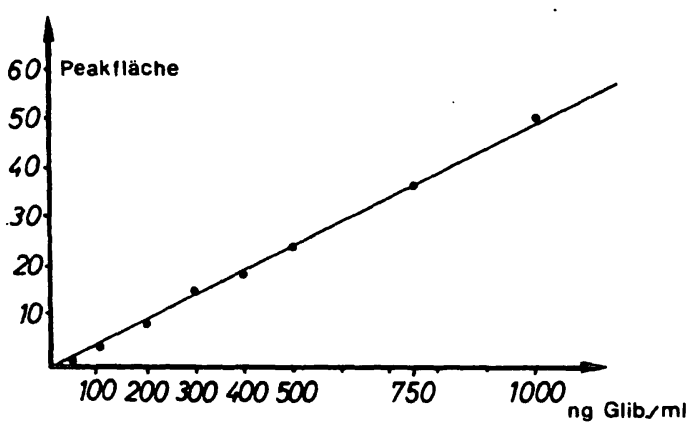

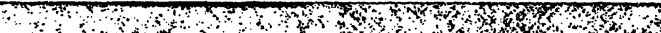

Die Kosten für die Einzelanalyse sind beim Radioimmunoassay höher als bei der Hochdruckflüssigkeitschromatographie, da radioaktiv markiertes Antigen und ein spezifischer Antikörper verwendet werden (Abb. 5).

Der Konzentrationsverlauf von Glibenclamid, Glucose und Insulin im Serum des Patienten ist in Abb. 6 dargestellt. Nach Einnahme einer Mahlzeit und $10 \mathrm{mg}$ Glibenclamid steigt in den folgenden drei Stunden die Glibenclamidkonzentration bis zu einem Maximum von $1000 \mathrm{ng} / \mathrm{ml}$ Serum an. Danach erfolgt ein annähernd exponentieller Abfall. Im Vergleich dazu steigt die Insulinkonzentration nach Mahlzeit und Glibenclamideinnahme von 18 auf etwa $60 \mu \mathrm{U} / \mathrm{ml}$ Serum an, wobei

\section{Abb. 5:}

Vergleich der Methoden zur Bestimmung von Sulfonylharnstoffen im Blut.

\begin{tabular}{lcc} 
& HPLC & RIA \\
\cline { 2 - 3 } PROBENVORBEREITUNG & $30 \mathrm{~min}$. & $180 \mathrm{~min}$. \\
ANALYSENZEIT & $10 \mathrm{~min}$. & $10 \mathrm{~min}$. \\
EMPFINDLICHKEIT & $10 \mathrm{ng} / \mathrm{ml}$ & $5 \mathrm{ng} / \mathrm{ml}$ \\
LINEARITÄT & $10-1000 \mathrm{ng} / \mathrm{ml}$ & $5.40 \mathrm{ng} / \mathrm{ml}$ \\
APP. AUFWAND & je Ca. DM 40000
\end{tabular}

$\underline{\text { RIA }}$

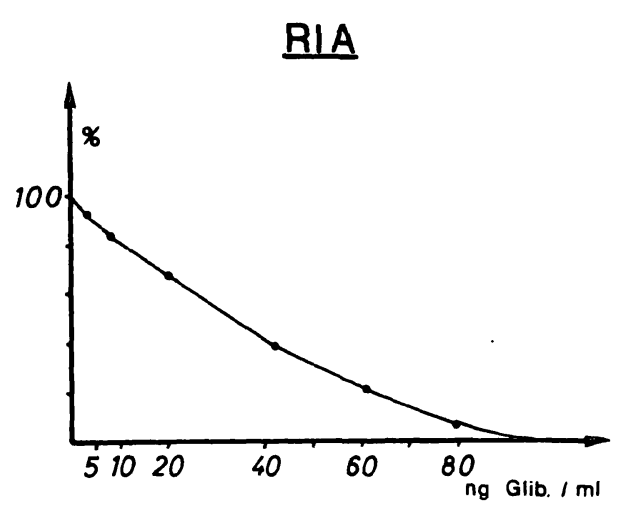

Abb. 6:

Änderung der Konzentrationen von Glibenclamid, von Glucose und Insulin im Blut nach einer Einnahme von $10 \mathrm{mg}$ Glibenclamid um $8.30 \mathrm{~h}$ morgens.

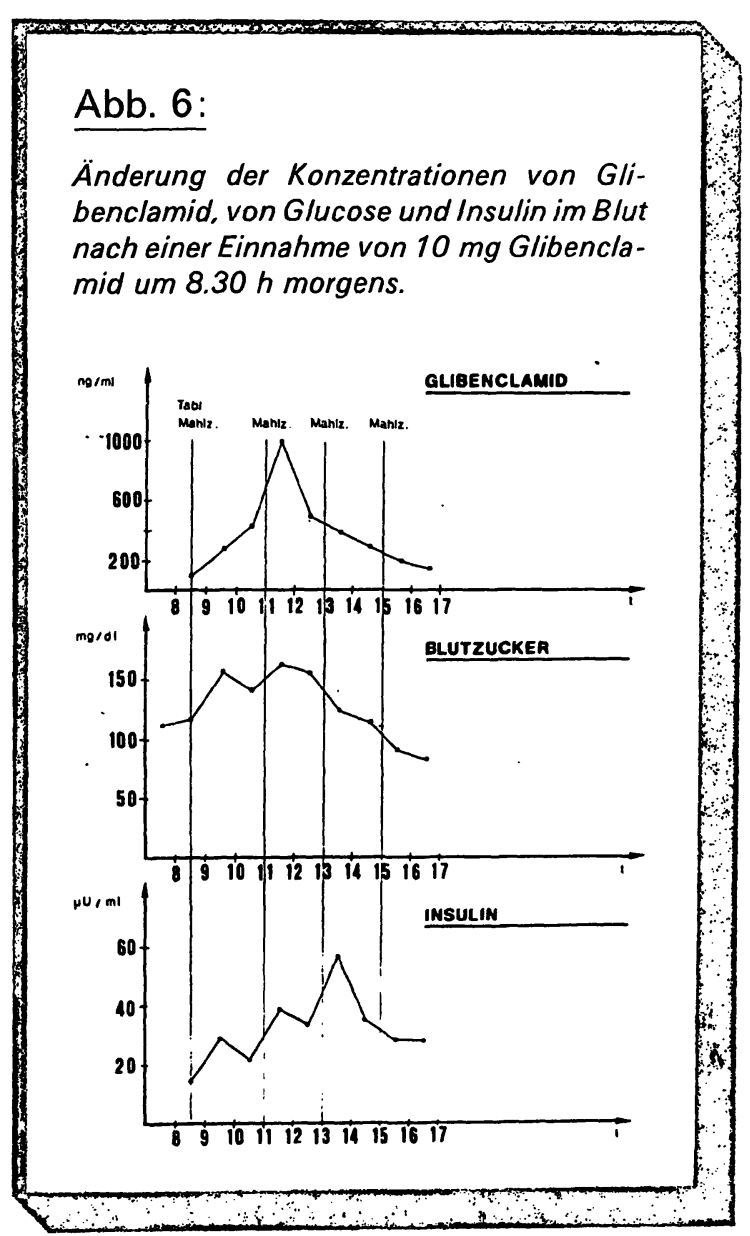




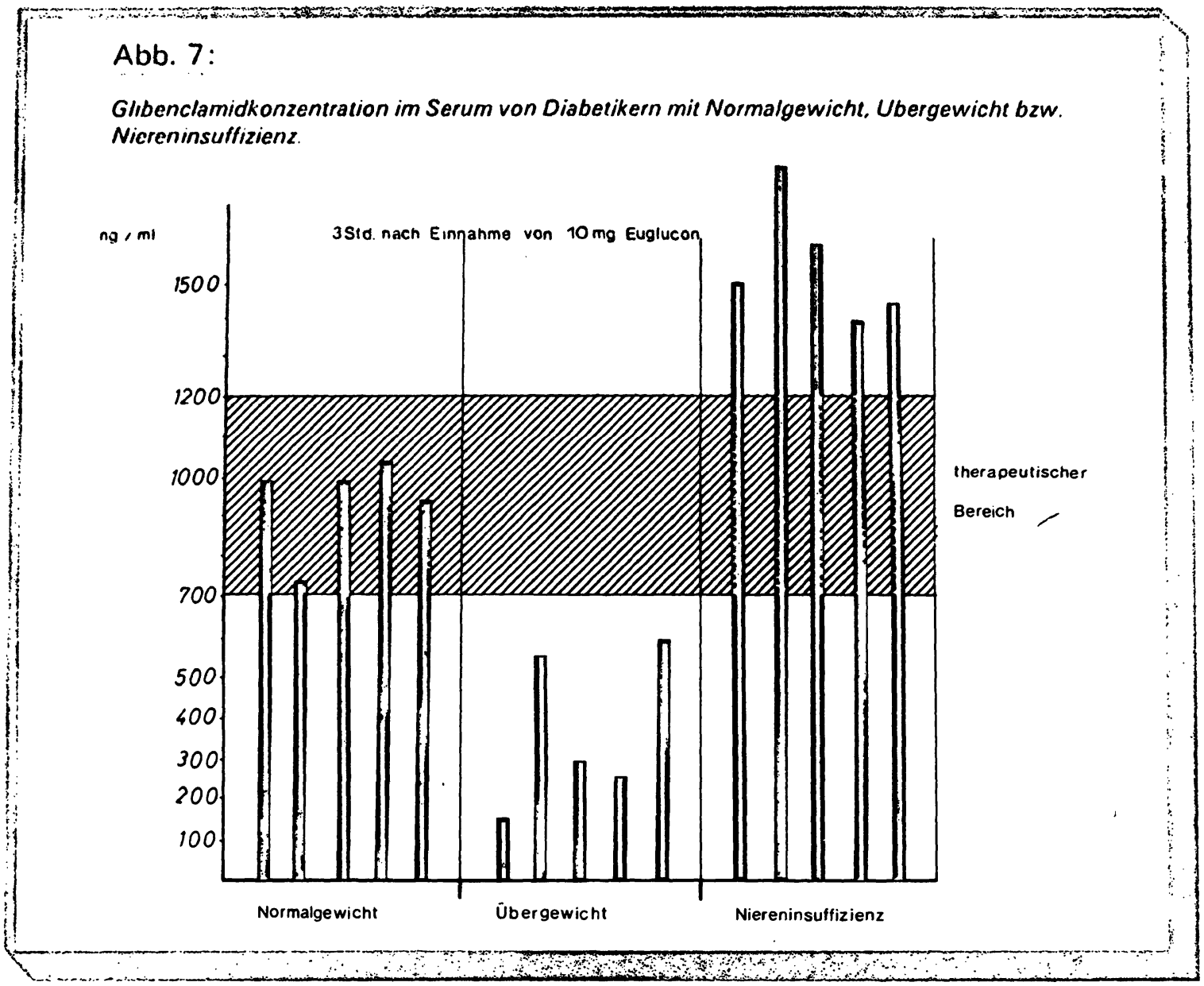

eine Phasenverschiebung von zwei Stunden gegenüber dem Konzentrationspeak des Glibenclamid zu beobachten ist. Die Blutzuckerkonzentration sinkt mit steigendem Insulinspiegel.

Die klinische Bedeutung der Bestimmung des Glibenclamidspiegels im Serum wird in drei von uns untersuchten Patientengruppen deutlich, nämlich bei normalgewichtigen, übergewichtigen und niereninsuffizienten Diabetikern, die alle morgens $10 \mathrm{mg}$ Glibenclamid einnahmen. Bei normalgewichtigen Altersdiabetikern findet man nach 3 Stunden Konzentrationen von $700-$ 1200 ng Glibenclamid/ml Serum. Bei Übergewichtigen wird dieser therapeutische Serumspiegel nicht erreicht. Dagegen liegt bei Niereninsuffizienten die Serumkonzentration aufgrund der verringerten Ausscheidung oberhalb des therapeutischen Bereiches (Abb. 7).

Anhand dieser drei Beispiele der Pharmakabestimmung im Serum wird erkennbar, daß es zu erheblichen Schwankungen des Glibenclamidserumspiegels von Diabetikern in Abhängigkeit von Körpergewicht und von der Nierenfunktion kommen kann.
Schrifttum:

1. HAJDU, P. KOHLER, K. F, SCHMIDT, F. H., SPÖNGLER, H.: Physikalischchemische und analytische Untersuchungen an HB 419. Arzneim. Forsch. 19, 13811386 (1969).

2. SCHMIDT, F. H., KOHLER, K. F., STORK, H., HAJDU, P.: Pharmakakinetische Untersuchungen mit dem neuen Antidiabetikum HB 419 am Tier. Arzneim. Forsch. 19, $1386-1388$ (1969).

3. KELER, H.-M., CHRIST, O., RUPP, W., HEPTNER, W.: Resorption, Verteilung und Ausscheidung nach Gabe von. ${ }^{14} \mathrm{C}$-markiertem $\mathrm{HB} 419$ an Kaninchen, Ratten und Hunden. Arzneim. Forsch. 19, 1388-1400 (1969).

4. HRSTKA, V. E., SCHMIDT, F. H.: Radioimmunologische Bestimmung von Glibenclamid. 8. Kongreß der Deutschen Diabetes-Gesellschaft, München 1973.

5. BRASELTON, W. E. jr., BRANSOME, E. D. jr., HUFF, T. A.: Measurement of antidiabetic sulfonylureas in serum by gas chromatography with electron-capture detection. Diabetes 26, 50-57, (1977).

6. SIMMONS, P L, RANZ R. J.PICOTTE, P.: Determination of serum tolbutamide by gas chromatography. J. Chromatogr. 71, $421-426$ (1972).

7. ENGELHARDT, H.: Hochdruck-Flüssigkeits-Chromatographie. Springer-Verlag, Berlin, Heidelberg, New York 1977.

Anschrift:

Prof. Dr. H. Reinauer

Diabetes-Forschungs-Institut an der Universität Düsseldorf,

Biochemische Abteilung

Auf'm Hennekamp 65

4000 Düsseldorf

Für die Überlassung des tritiummarkierten Antigens und des spezifischen Antikörpers danken wir Herrn Dr. Hrstka, Boehringer, Mannheim. 